\title{
Arranjos Institucionais e Desenvolvimento: uma Análise Multivariada e Espacial para Municípios de Minas Gerais
}

\section{Institutional Arrangements and Development: a Multivariate and Spacial Analysis for Minas Gerais' Cities}

\author{
Hilton Manoel D. Ribeiro* \\ Suzana Quinet A. Bastos** \\ Ana Maria Hermeto***
}

\begin{abstract}
Resumo: O objetivo deste trabalho é analisar a relação entre o desenvolvimento socioeconômico e o arranjo institucional dos municípios do estado de Minas Gerais. Para tanto, a metodologia envolve a análise de correspondência associada à análise de regressão ponderada geograficamente. $\mathrm{O}$ índice Firjan de desenvolvimento municipal (IFDM) é utilizado como indicador de desenvolvimento municipal. Como variáveis explicativas que formam o arranjo institucional, quatro indicadores institucionais e mais quatro variáveis relacionadas aos gastos públicos são utilizados. Os resultados revelam uma associação direta entre os municípios que possuem mais instrumentos institucionais formais, como, por exemplo, programas de geração de trabalho e renda e políticas de apoio ao primeiro emprego, e altos níveis do IFDM. Assim, a compreensão do tipo de associação entre os instrumentos institucionais formais e o grau de desenvolvimento dos municípios pode ampliar as discussões sobre os desequilíbrios regionais em Minas Gerais.
\end{abstract}

Palavras-chave: Instituições. Desenvolvimento regional. Análise espacial.

Abstract: The objective of this study is to analyze the relationship between socioeconomic development and the institutional arrangements of the cities of Minas Gerais' state. Therefore, the methodology involved the correspondence analysis associated with weighted regression geographically. The FIRJAN Municipal Development Index (FMDI) was used as a municipal development indicator. As explanatory variables that form the institutional arrangement, four indicators institutional and four variables related to public expenditures were used. The results showed a direct association between cities that have more formal institutional instruments such as, for example, job and income generation programs and support policies to first jobs, and high levels of FMDI. Thus, understanding the type of association between the formal institutional instruments and the degree of the cities' development could expand the discussion about regional inequalities in Minas Gerais.

* Doutor em Economia pela Universidade Federal de Juiz de Fora (UFJF). Professor no Departamento de Economia da UFJF-Campus GV. Coordenador do GEEA/UFJF-GV. E-mail: hilton.manoel@uff.edu.br

** Doutora em Planejamento Urbano e Regional pela Universidade Federal do Rio de Janeiro (UFRJ). Professora titular no Departamento de Economia e no PPGE - Universidade Federal de Juiz de Fora (UFJF).E-mail: quinet.bastos@ufff.edu.br

*** Doutora em Demografia pela Universidade Federal de Minas Gerais (UFMG). Professora Associada no Departamento de Economia e no CEDEPLAR- Universidade Federal de Minas Gerais (UFMG). E-mail: ahermeto@cedeplar.ufmg.br 
Keywords: Institutions. Regional development. Spatial analysis.

JEL Classification: $\mathrm{C} 31$; O10; O17.

\section{Introdução}

A discussão acerca do processo de desenvolvimento das regiões está ancorada numa série de formulações teóricas e análises empíricas que contempla aspectos ligados à industrialização e infraestrutura, à formação de recursos humanos, à inovação e ao nível de atividade econômica, entre outros. Ademais, outras dimensões foram se revelando importantes para a compreensão de outro sentido do desenvolvimento, que vai além dos fatores puramente econômicos já conhecidos.

As teorias de desenvolvimento foram ganhando novos contornos, e essas mudanças tiveram reflexo no entendimento do subdesenvolvimento em alguns países e regiões, como no caso do Brasil, onde se registram altos índices de desigualdades regionais, em diferentes níveis de desagregação territorial. Essas contradições ficam em destaque quando se comparam regiões como o Sudeste e o Nordeste brasileiro, ou, mesmo, diferentes regiões de um estado, como é verificado em Minas Gerais.

Uma avaliação da participação do Produto Interno Bruto -PIB (ver Tabela 1) das mesorregiões mineiras no valor total do estado corrobora essa heterogeneidade. Observa-se uma participação relativamente constante ao longo do tempo para todas as regiões, e, ao se verificar os dados para o ano de 2010, percebe-se a discrepância entre as regiões do eixo Norte/Nordeste frente ao eixo central/Sul. Somente a região metropolitana de Belo Horizonte corresponde a mais de $40 \%$ dessa participação, enquanto as regiões Norte e Nordeste somadas (Norte de Minas, Jequitinhonha e Mucuri) não ultrapassam 6\%.

Tabela 1 - Participação das mesorregiões no PIB de Minas Gerais

\begin{tabular}{l|c|c|c}
\hline Mesorregião & $\mathbf{2 0 0 0}(\%)$ & $\mathbf{2 0 0 5}(\%)$ & $\mathbf{2 0 1 0}(\%)$ \\
\hline Norte de Minas & 4,03 & 4,01 & 3,86 \\
Jequitinhonha & 1,28 & 1,18 & 1,18 \\
Vale do Mucuri & 0,92 & 0,87 & 0,86 \\
Noroeste de Minas & 1,62 & 1,80 & 1,71 \\
Triângulo Mineiro/Alto Paranaíba & 15,37 & 15,24 & 15,00 \\
Central Mineira & 1,63 & 1,75 & 1,65 \\
Metropolitana de Belo Horizonte & 40,71 & 41,84 & 45,02 \\
Vale do Rio Doce & 6,67 & 6,82 & 5,97 \\
Oeste de Minas & 3,84 & 4,07 & 3,75 \\
\hline
\end{tabular}


conclusão.

\begin{tabular}{l|c|c|c}
\hline Mesorregião & $\mathbf{2 0 0 0}(\%)$ & $\mathbf{2 0 0 5}(\%)$ & $\mathbf{2 0 1 0}(\%)$ \\
\hline Sul/Sudoeste de Minas & 13,22 & 12,31 & 11,77 \\
Campo das Vertentes & 2,15 & 2,13 & 1,93 \\
Zona da Mata & 8,56 & 7,99 & 7,29 \\
Total & 100,00 & 100,00 & 100,00 \\
\hline
\end{tabular}

Fonte: Elaboração própria a partir de dados da Fundação João Pinheiro (2013).

Diniz (2001) destaca a globalização como força modificadora das relações entre o global e o local. Para Albagli (1999), os avanços na teoria do desenvolvimento regional mostram que a globalização não elimina os contextos sociais e institucionais, ao contrário, reforça essas dimensões, o que contribui para o aumento da competitividade interterritorial, podendo, em consequência, acentuar as disparidades regionais.

Assim, o objetivo central envolve um esforço interdisciplinar na análise do desenvolvimento dos municípios mineiros, enfatizando a importância dos aspectos relativamente menos tangíveis, como os de caráter institucional ligados à ação do Estado, para o entendimento do processo de desenvolvimento. Daqui, surgem os seguintes questionamentos: os arranjos institucionais estão relacionados com o desempenho dos indicadores socioeconômicos municipais? Qual a direção dessa relação?

Para a consecução deste objetivo utilizam-se dois métodos de análise. O primeiro refere-se à análise de correspondência e o segundo ao método de regressão ponderada geograficamente, ambos se complementando no intuito de identificar associações entre o indicador de desenvolvimento econômico - nesse caso, o Índice Firjan de Desenvolvimento Municipal (IFDM) - e as variáveis ligadas à ação do Estado, ou seja, indicadores de caráter institucional. O período de análise é o ano de 2009 (análise cross-section).

A importância de se compreender os aspectos institucionais se faz fundamental tendo em vista que a partir da Constituição de 1988 os municípios adquiriram autonomia política, através da elaboração de sua própria lei orgânica e demais leis. Além disso, ampliaram sua competência em áreas importantes como a política urbana, transporte coletivo, assistência social, meio ambiente, habitação, saneamento, produção agropecuária, abastecimento alimentar, educação, saúde, entre outros.

Assim, os distintos arranjos institucionais em termos de leis, normas, diretrizes, apoio, fundos, entre outros influenciam no desempenho socioeconômico dos municípios. Além disso, o Estado enquanto unidade que articula uma rede de agentes locais tem reflexos sobre a dinâmica de desenvolvimento. Ou seja, não se devem desconsiderar os efeitos que as instituições locais (cooperativas, sindicatos, 
associações etc.) bem como as regras e políticas que as constituem (legislação, cultura, capital social etc.) exercem sobre a desempenho socioeconômico municipal.

Este trabalho divide-se da seguinte forma: Além desta introdução, o Capítulo 2 apresenta a revisão de literatura com foco na discussão entre instituições e desenvolvimento; o Capítulo 3 indica a metodologia e as bases de dados; o Capítulo 4 apresenta e discute os resultados; e por fim o Capítulo 5 traz as considerações finais.

\section{Instituições e Desenvolvimento}

O desenvolvimento econômico é a grande meta do planejamento público e, por isso, a formulação de políticas públicas está condicionada ao entendimento dos diversos aspectos relacionados a esse processo. Os estudos acerca do desenvolvimento das regiões foram avançando do sentido unidimensional (dimensão econômica) para o sentido multidimensional (saúde, cultura, educação, social, institucional, entre outros).

Para Reis (2006), as articulações focadas em desenvolvimento regional necessitam de uma lógica institucional (formal ou não) que possa dinamizar a relação entre os agentes econômicos, como, por exemplo, os conselhos de desenvolvimento, consórcios intermunicipais, sindicatos de produtores rurais, núcleos de pesquisa, cooperativas, associações comunitárias, movimentos sociais e a própria interação entre universidades, empresas e governo.

Araújo, Melo e Schommer (2005) argumentam que o desenvolvimento econômico depende da melhoria da capacidade de organização da sociedade civil, da participação ativa dos cidadãos, de uma cooperação social intensa e da integração das políticas urbanas. North (1990), por seu turno, defende que a chave do desenvolvimento não está somente em vantagens naturais ou acumulação de capital, mas também nas instituições enraizadas em determinada localidade.

Diniz e Crocco (2006) destacam três perspectivas dos marcos teóricos da política regional e urbana: a primeira com caráter keynesiano, a segunda com o enfoque da competitividade e a terceira com a busca de uma terceira geração de políticas regionais (exógena-endógena). A mudança da primeira (exógena) para a segunda perspectiva (endógena) envolve duas mudanças importantes: a valorização da capacitação local na formulação de políticas e a incorporação de aspectos institucionais (tais como conhecimento, massa crítica, capital social e cultura) no entendimento das dinâmicas regionais. Assim, em vez de se rebater as políticas de caráter exógeno (Estado interventor), ou as políticas de caráter endógeno (Estado mínimo), tem-se como novo a síntese entre essas duas concepções, que consiste na volta da participação do Estado levando-se em conta a implementação das políticas regionais em conjunto com as nacionais. 
As "sinergias da sociedade-Estado", conforme Evans (1996), podem ser um catalisador para o desenvolvimento. Normas de cooperação e redes de cidadania e compromisso entre os cidadãos podem ser promovidos por órgãos públicos e utilizados para fins de desenvolvimento. As redes de confiança e colaboração que são criadas abrangem a fronteira do público-privado e vinculam o Estado e a sociedade civil.

Para Fiani (2011), o papel do Estado enquanto instituição reguladora e promotora do desenvolvimento percorre sua capacidade de promover arranjos institucionais adequados ao funcionamento da economia e até o de contribuir com a criação de um arranjo institucional favorável para que os agentes se articulem sobre essa base.

Chang (2003), resgatando Williamson (1985), observa que os ativos específicos desempenham um papel importante no sistema econômico (localização, atributos físicos, ativos dedicados e ativos humanos). ${ }^{1}$ Nesses ativos, a coordenação pelo mercado por meio de mecanismos de preços pode ser importante fonte de desperdícios de recursos econômicos. Esse mecanismo realiza uma coordenação ex post das atividades, ou seja, coordena as atividades somente depois das decisões de investimento já terem se concretizado, o que pode implicar decisões equivocadas (considerando a racionalidade limitada dos indivíduos). Disso, segundo Chang (1996), resulta a necessidade uma coordenação ex ante, ou seja, antes que a decisão de investimento se concretize. Essas questões oferecem ao Estado o papel de gestor de conflitos ou de empreendedor.

Dessa forma, segundo Healey (1997), para se incorporar a abordagem institucionalista no entendimento da dinâmica regional deve-se rejeitar a função neoclássica de utilidade, dos indivíduos autônomos buscando sua própria satisfação, para uma nova dimensão em que as instituições interferem na dinâmica de desenvolvimento. A teoria institucional dá ênfase ao fluxo das relações sociais em que a vida social é um processo ativo e contínuo de interação entre os indivíduos, o que nada mais é do que a construção de vínculos relacionais. Além disso, deve-se pensar como esses vínculos se expressam na forma de direitos e regras formais, organizados pelo Estado, capazes de determinar o desenvolvimento.

Assim, as políticas de Estado voltadas para o desenvolvimento regional devem fomentar a construção e promoção de quadros institucionais que garantam a aproximação de capacidades e habilidades, alimentando redes sociais em meio aos conflitos de interesses. É sob essa abordagem que se questiona a própria formulação de políticas para diminuição das desigualdades regionais em Minas Gerais, sabendo que as próprias diferenças se encontram presentes nesses arranjos

1 Localização se refere aos elevados custos de construção e deslocamento; atributos físicos se referem à individualidade do ativo em relação aos demais; ativos dedicados se referem ao fato de que o investimento é realizado vinculado a uma demanda específica no futuro; especificidade de ativos humanos se refere ao "aprender fazendo" e ao trabalho em equipe (FIANI, 2011, p. 98). 
institucionais e de interação entre os diversos agentes da sociedade, nos diferentes municípios e regiões.

\section{Metodologia e Bases de dados}

O uso de análise multivariada associada às técnicas de econometria espacial permite explicar a interdependência entre variáveis institucionais, gastos públicos e o indicador socioeconômico para os municípios mineiros. A conjunção desses métodos permite confirmar a existência de padrões de associação e, assim, se complementam, dado que o primeiro método permite identificar esse perfil de associação global e o segundo método, além de indicar o perfil e o nível dessa associação, contempla uma análise dessas relações no nível local (para cada município), acomodando e avaliando a instabilidade das relações entre as variáveis através do espaço.

\subsection{Análise de Correspondência}

A análise de correspondência (AC) é uma técnica que busca reduzir a dimensão da cotação dos objetos que podem ser pessoas, produtos ou classes em um subconjunto, permitindo a representação gráfica dos objetos em relação aos atributos. Dessa forma, é possível compreender as relações entre os elementos (linha e coluna) em que a proximidade representa uma forte associação enquanto que o distanciamento representa o contrário. Segundo Coppola (2003, p. 16), "We can distinguee the simple correspondence analysis and the multiple one, in the first only the association amongst the row and column variables are analyzed, in the second also the association between each variables and itself".

Para Souza, Bastos e Vieira (2010) e Gonçalves e Santos (2009), esse método facilita a análise de dados categóricos, pois permite analisar graficamente as relações através da redução de dimensionalidade da base de dados. Tal técnica é aplicada a uma tabela de contingência para determinar o grau de associação global entre linhas e colunas e baseia-se na decomposição do valor singular de uma matriz retangular, representando graficamente as linhas e as colunas como pontos em espaços vetoriais de pequena dimensão.

Os resultados gráficos contribuem para avaliar visualmente se as variáveis de interesse se afastam do pressuposto de independência, sugerindo a existência e a conformação das associações e, ainda, percebendo como acontece essa associação. Os níveis das variáveis de linha e de coluna assumem posições nos gráficos de acordo com a associação ou similaridade entre elas (GREENACRE, 1984; LEBART; MORINEAU; WARWICK, 1977; LEBART MORINEAU; FÉNELON, 1984). 
Para Czermainski (2004), essa ferramenta revela relações que não teriam sido percebidas se a análise fosse feita aos pares de variáveis. Além disso, é flexível no tratamento dos dados, por não ser necessária a adoção de modelo teórico de distribuição de probabilidade, bastando uma matriz retangular com dados não negativos.

A tabela de contingência é a forma de organização dos dados, em que cada elemento $n_{i j}$ representa um elemento pertencente à categoria $i$ da variável $A$ e à categoria $j$ da variável $B$. Para se verificar as associações existentes entre as variáveis $A$ e $B$, representadas pelas categorias $i$ e j, extrai-se uma matriz que transforma cada frequência observada em uma proporção ou probabilidade $\left(P_{i x j}\right)$, conforme (1):

$$
P_{i x j}=n_{i j} / n
$$

em que $P_{i x j}$ representa uma proporção de explicação da frequência $n_{i j}$ em relação ao total $n$.

De acordo com Alves, Belderrain e Scarpel (2007), na representação bidimensional é possível verificar a projeção dos pontos originais sobre um plano, mas não é possível averiguar quais estão mais próximos ou mais distantes. ${ }^{2} \mathrm{O}$ ideal é se ter o conhecimento da geometria de um conjunto de pontos em um espaço multidimensional, e, a partir dos princípios geométricos da AC, é possível representar dentro do espaço euclidiano as distâncias entre os pontos. Dessa forma, tem-se o gráfico denominado mapa de correspondência ou mapa perceptual, que facilita a visualização das relações existentes entre as variáveis. ${ }^{3}$

Pela análise gráfica é gerada uma nuvem de pontos contidos em um espaço multidimensional que dificulta a avaliação apenas visual. Contudo, essa nuvem pode ser projetada em planos escolhidos pela sua capacidade de representar as distâncias originais dos pontos da forma mais fidedigna. Nesses planos, os pontos se distribuem segundo sua representatividade, revelando que perfis semelhantes se localizam mais próximos do que pontos advindos de perfis com características divergentes (GONÇALVES E SANTOS, 2009).

A análise de correspondência múltipla (ACM) é uma extensão da análise de correspondência simples para mais de duas variáveis. Esta analisa uma tabela de contingência de duas vias, enquanto aquela analisa uma tabela multiponto ${ }^{4}$ (STATACORP, 2009).

$2 \quad$ Ver Faria (1993).

3 Ver Lourenço (1997).

$4 \quad$ Para mais detalhes, ver Everitt e Landau (2001), Gower e Hand (1996) e Greenacre (2007). 


\subsection{Regressão Ponderada Geograficamente (RPG)}

Para Freitas e Almeida (2015) e Ribeiro e Almeida (2012), a principal vantagem do modelo RPG é a estimação de um modelo específico para cada região, controlando para a heterogeneidade espacial extrema. Assim, essa metodologia permite o controle da dependência espacial (nas formas de defasagem espacial, de erro e de transbordamentos da variável explicativa) e dos efeitos não observados.

Essa modelagem foi desenvolvida por Fotheringhan, Brundsdon e Charlton (2002), baseando-se na análise de regressão tradicional, incorporando a estimação de coeficientes locais para cada região, usando subamostras dos dados. As regiões que fazem parte das subamostras são escolhidas de acordo com as suas distâncias em relação ao local para o qual está sendo calculada a regressão. O modelo admite que dados mais próximos exerçam maior influência do que dados relativos às áreas mais distantes. O modelo RPG se descreve conforme (2):

$$
y_{i}=\beta_{0}\left(u_{i}, v_{i}\right)+\Sigma_{k} \beta_{k}\left(u_{i}, v_{i}\right) x_{i k}+\varepsilon_{i}
$$

em que $y_{i}$ representa a variável dependente; $\left(u_{i}, v_{i}\right)$ representam as coordenadas do ponto $i$ no espaço, $\beta_{k}\left(u_{i}, v_{i}\right)$ representa o valor que a função contínua $\beta_{k}(u, v)$ assume no ponto i para o conjunto de variáveis explicativas $x$ e $\varepsilon$ representa o erro da regressão.

A estimação de $\beta\left(u_{i}, v_{i}\right)$ é feita por mínimos quadrados ponderados, em que os pesos modificam-se sob influência da proximidade com o ponto de regressão $i$. O estimador de RPG é dado por (3):

$$
\beta\left[u_{i}, v_{i}\right]=\left(X^{\prime} W\left[u_{i}, v_{i}\right] X\right)^{-1} X^{\prime} W\left[u_{i}, v_{i}\right] Y
$$

em que $W$ é uma matriz de ponderação fixa ou adaptativa e $w_{i j}$ indica os pesos baseados na distância entre a observação no ponto i e as demais observações da subamostra selecionada pela função do kernel ${ }^{5}$ espacial (largura da banda baseada na matriz $W$ ).

Para Almeida (2012), a largura da banda pode ser fixa ou adaptativa. No kernel adaptativo, a banda se adapta ao número de observações em torno do ponto a ser observado, obtendo estimações mais eficientes e menos enviesadas. Por essa razão é que é utilizada neste trabalho. Nas áreas na quais as observações são mais escassas, o kernel se expande, e quando as observações são mais abundantes, o kernel encolhe.

$5 \quad$ Consultar Almeida (2012). 
Nos resultados da regressão, observam-se os coeficientes tanto para o modelo global, quanto para o modelo local. Sobre os coeficientes locais, realiza-se uma análise de variabilidade geográfica, confirmando-se a adequação do modelo RPG para os dados em questão. Assim, um valor positivo do "DIFF of criterion", ${ }^{6}$ especialmente maior ou igual a dois, sugere que o coeficiente global seja assumido no lugar do coeficiente local, indicando não variabilidade espacial. Ao possibilitar a estimação dos parâmetros considerando sua variabilidade espacial, a metodologia RPG avança na solução da omissão da heterogeneidade espacial nos parâmetros.

\subsection{Bases de Dados}

O Índice Firjan de Desenvolvimento Municipal - IFDM é a variável dependente. Esse indicador é composto por três dimensões: a primeira refere-se a emprego/renda, que contempla variáveis como a geração de emprego formal, o estoque de emprego formal e os salários médios do emprego formal; a segunda refere-se à educação, que contempla a taxa de matrícula na educação infantil, a taxa de abandono, a taxa de distorção idade-série, o percentual de docentes com ensino superior, a média de horas aula diária e o resultado do Índice de Desenvolvimento da Educação Básica (Ideb); e a terceira refere-se à saúde, que contempla o número de consultas pré-natal, os óbitos infantis por causas evitáveis e os óbitos por causas mal definidas (FEDERAÇÃO DAS INDÚSTRIAS DO ESTADO DO RIO DE JANEIRO, 2013).

O grupo de variáveis explicativas é formado por quatro indicadores "institucionais" das áreas de planejamento (plan), gestão (gest), educação (edu) e saúde (sau), os quais foram criados a partir das variáveis binárias da Pesquisa de Informações Básicas Municipais (MUNIC) de 2009, extraídas do Instituto Brasileiro de Geografia e Estatística (IBGE, 2013). Ainda, quatro variáveis relacionadas aos gastos públicos, nas áreas de educação (gedu), saúde (gsau), investimento (inv) e outros gastos (gout), foram obtidas da Fundação João Pinheiro (FUNDAÇÃO JOÃO PINHEIRO, 2013), conforme a Tabela 2. Estas últimas representam o tamanho do Estado em áreas relacionadas ao indicador de desenvolvimento.

6 Indica a diferença nos critérios de comparação entre modelos. 
Tabela 2 - Base de dados

\begin{tabular}{|c|c|c|c|}
\hline & Variável $^{1}$ & Descrição & Fonte \\
\hline Variável dependente & IFDM & $\begin{array}{l}\text { Índice Firjan de Desenvolvimento } \\
\text { Municipal. }\end{array}$ & Firjan \\
\hline \multirow{4}{*}{$\begin{array}{l}\text { Variáveis explica- } \\
\text { tivas categóricas: } \\
\text { instituições }\end{array}$} & plan & $\begin{array}{l}\text { Legislação e instrumentos de plane- } \\
\text { jamento no município: construção } \\
\text { a partir das variáveis A26, A38, } \\
\text { A47, A48, A49, A51, A52, A53, } \\
\text { A54, A55, A56 e A57. }\end{array}$ & IBGE \\
\hline & gest & $\begin{array}{l}\text { Recursos para gestão: construção } \\
\text { a partir das variáveis A85, A110, } \\
\text { A119, A120, A121, A122, A123, } \\
\text { A124, A126, A127, A128 e A129. }\end{array}$ & IBGE \\
\hline & edu & $\begin{array}{l}\text { Educação: construção a partir das } \\
\text { variáveis A171, A179, A180, A181, } \\
\text { A182, A183, A184, A185, A187, } \\
\text { A211, A220, A221, A222, A223 e } \\
\text { A224. }\end{array}$ & IBGE \\
\hline & sau & $\begin{array}{l}\text { Saúde: construção a partir das } \\
\text { variáveis A391, A399, A401, A409, } \\
\text { A414, A415, A416, A417 e A418. }\end{array}$ & IBGE \\
\hline \multirow{4}{*}{$\begin{array}{l}\text { Variáveis explicati- } \\
\text { vas contínuas: gastos } \\
\text { públicos }\end{array}$} & gedu & Gastos per capita com educação. & FJP \\
\hline & gesau & Gastos per capita com saúde. & FJP \\
\hline & gout $^{3}$ & Gastos per capita outros. & FJP \\
\hline & inv & $\begin{array}{l}\text { Esforço de investimento: razão en- } \\
\text { tre as despesas que a administração } \\
\text { pública realiza com investimentos e } \\
\text { o total de seus gastos, multiplicado } \\
\text { por } 100 .\end{array}$ & FJP \\
\hline
\end{tabular}

Fonte: Elaboração própria.

Notas: ${ }^{1}$ IFDM em número índice (entre 0 e 1); variáveis institucionais categóricas (três níveis para análise de correspondência; e binárias para RPG); variáveis contínuas na forma de logaritmo natural; ${ }^{2}$ ver descrição dos códigos no Apêndice A; ${ }^{3}$ gasto per capita total menos gastos per capita com saúde e educação ( $R$ \$ dez./2010).

A construção dos indicadores categóricos "institucionais" baseou-se na disponibilidade de respostas da MUNIC. Esses indicadores formam o arranjo institucional de cada município. Por exemplo, para o indicador institucional de saúde (sau), consideram-se nove variáveis. Assim, o município que apresenta a afirmativa "sim" para todas as variáveis apresenta nota máxima igual a nove, ou seja, aqueles municípios que possuem bom indicador institucional de saúde estão mais 
próximos de nove e os que apresentam baixo indicador estão mais próximos de zero. Além disso, para fins de padronização de categorias, as variáveis foram categorizadas em três níveis: baixo (1), médio (2) e alto (3).

A Tabela 3 apresenta os resultados da correlação entre as variáveis. Verifica-se que não existe, no geral, uma correlação alta entre as variáveis, com exceção para a correlação entre gastos com educação e outros gastos, que ficou acima de 0,7.

Tabela 3 - Correlação entre variáveis

\begin{tabular}{l|ccccccccc}
\hline & IFDM & plan & gest & edu & sau & gedu & gesau & gout & inv \\
\hline IFDM & 1 & & & & & & & & \\
plan & 0,2495 & 1 & & & & & & & \\
gest & 0,0837 & 0,3835 & 1 & & & & & & \\
edu & 0,0618 & 0,2432 & 0,2518 & 1 & & & & & \\
sal & 0,0296 & 0,1636 & 0,137 & 0,1626 & 1 & & & & \\
gedu & 0,0891 & $-0,0196$ & $-0,0397$ & $-0,0186$ & $-0,0147$ & 1 & & & \\
gesau & 0,1946 & 0,0222 & $-0,0309$ & 0,0197 & 0,012 & 0,696 & 1 & & \\
gout & 0,1576 & $-0,0192$ & 0,0024 & $-0,0128$ & 0,0056 & 0,7333 & 0,662 & 1 & \\
inv & 0,0993 & 0,0249 & 0,061 & $-0,0127$ & 0,0161 & 0,1285 & 0,0283 & 0,1116 & 1 \\
\hline
\end{tabular}

Fonte: Elaboração própria.

\subsubsection{Análise Exploratória de Dados Espaciais (AEDE)}

Na Figura 1 busca-se a existência de algum padrão espacial do IFDM. Nota-se uma concentração de municípios com alto indicador nas partes centro e Sul e outra concentração de municípios com baixo valor do indicador nas partes Norte e Nordeste do estado de Minas Gerais.

Definindo-se a matriz de $K$ vizinhos segundo o procedimento de Baumont (2004), tem-se que a matriz com quatro vizinhos apresenta o maior valor do I de Moran, sendo a que melhor se ajusta à análise. Vale ressaltar que o procedimento de testar diretamente os erros da regressão também indica a matriz com quatro vizinhos. 


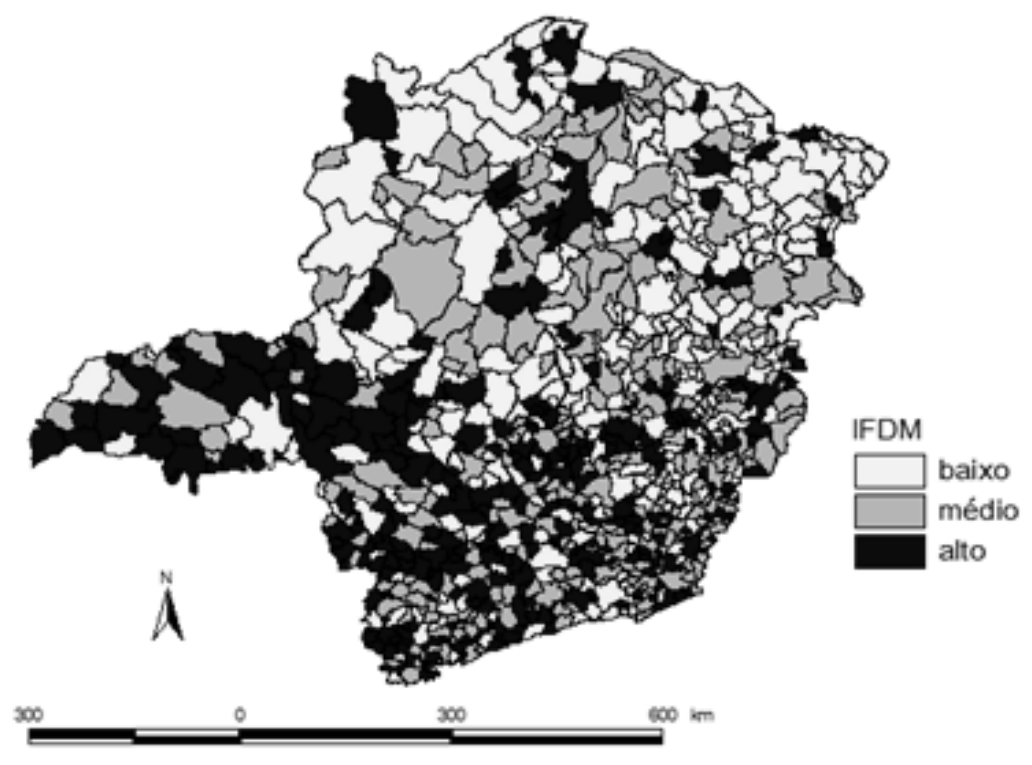

Fonte: Elaboração própria.

Após a AEDE, é preciso verificar se os dados espaciais apresentam aleatoriedade ou dependência espacial, isto é, se os valores de uma variável em uma região são independentes ou não dos valores dessa variável nas regiões vizinhas.

Caso o valor da variável de interesse $y_{i}$ (IFDM) seja independente dos valores dos municípios vizinhos $(\mathrm{Wy})$, o que indica aleatoriedade espacial, o valor calculado do I de Moran deve ser igual ao valor esperado de -[1/(n-1)], que se aproxima de zero à medida que $n$ aumenta. Valores acima do valor esperado indicam autocorrelação espacial positiva, isto é, altos valores de um atributo de um município tendem a ser vizinhos de altos valores de outros municípios, e baixos valores de alguns municípios também tendem a se agrupar. Nesse caso, há similaridade entre os valores do atributo estudado e o de sua localização espacial, indicando um padrão de concentração. Ao contrário, se há uma autocorrelação espacial negativa, altos valores do atributo estudado tendem ser vizinhos de baixos valores e vice-versa, indicando um padrão de dispersão.

O I de Moran Global univariado é de 0,5682, e, a um nível de significância de $1 \%$, rejeita-se a hipótese de aleatoriedade espacial para a variável em questão. A partir desse valor, há evidências de autocorrelação espacial positiva, ou seja, municípios com IFDM acima da média são vizinhos de municípios com IFDM também acima da média. Indica-se que há uma similaridade entre o IFDM e a localização. 
Outra medida de autocorrelação global espacial é a estatística $c$ de Geary: ${ }^{7}$ o numerador é uma medida de covariância entre os valores da variável de interesse, na forma do quadrado da diferença entre pares $\left(y_{i}\right.$ e $\left.y_{j}\right)$, ponderados pela matriz espacial; e o denominador é uma medida de variância. O valor do $c$ de Geary situa-se entre 0 e 2 , ao passo que o seu valor esperado é 1 . Valores menores que o seu valor esperado $(0<c<1)$ indicam autocorrelação espacial positiva, enquanto que valores maiores que $1(1<c<2)$ indicam autocorrelação espacial negativa. À medida que $n$ eleva-se, a estatística $c$ é distribuída assintoticamente de acordo com uma normal (ALMEIDA, 2012). O valor de $c$ é igual a 0,3737, indicando concentração espacial dos dados.

Na situação em que padrões de associação espacial estejam concentrados em poucos municípios (clusters espaciais), uma estatística global pode não refletir essa concentração. As associações espaciais locais podem ser identificadas por meio de estatísticas locais de autocorrelação espacial, como o indicador local indicator of spatial association (Lisa). ${ }^{8}$

A Figura 2 revela os clusters para a variável dependente IFDM. Os municípios com baixo IFDM são rodeados por municípios com o mesmo perfil (baixo/ baixo), enquanto municípios com alto IFDM são rodeados por municípios com esse perfil (alto/alto), indicando algum grau de associação espacial dessa variável. O traço representa uma divisão entre as regiões Norte e Sul de Minas Gerais, onde os municípios menos desenvolvidos (do tipo baixo-baixo) estão mais ao Norte, enquanto os municípios mais desenvolvidos (alto-alto) estão mais ao Sul. Como exemplo, citam-se os municípios de Jequitinhonha e de Uberlândia, para o primeiro e segundo caso, respectivamente.

7 As estatísticas I e c indicam autocorrelação positiva (concentração), enquanto negativo significa dispersão. Portanto, o c de Geary, assim como o I de Moran são utilizados para se detectar aleatoriedade ou dependência espacial. Como utilizam medidas diferentes em seu cálculo, o emprego das duas neste trabalho serve para confirmar essa aleatoriedade ou dependência espacial.

8 Para mais detalhes sobre a formulação matemática do Lisa, consultar Anselin (1995). 
Figura 2 - Indicador Lisa para o IFDM

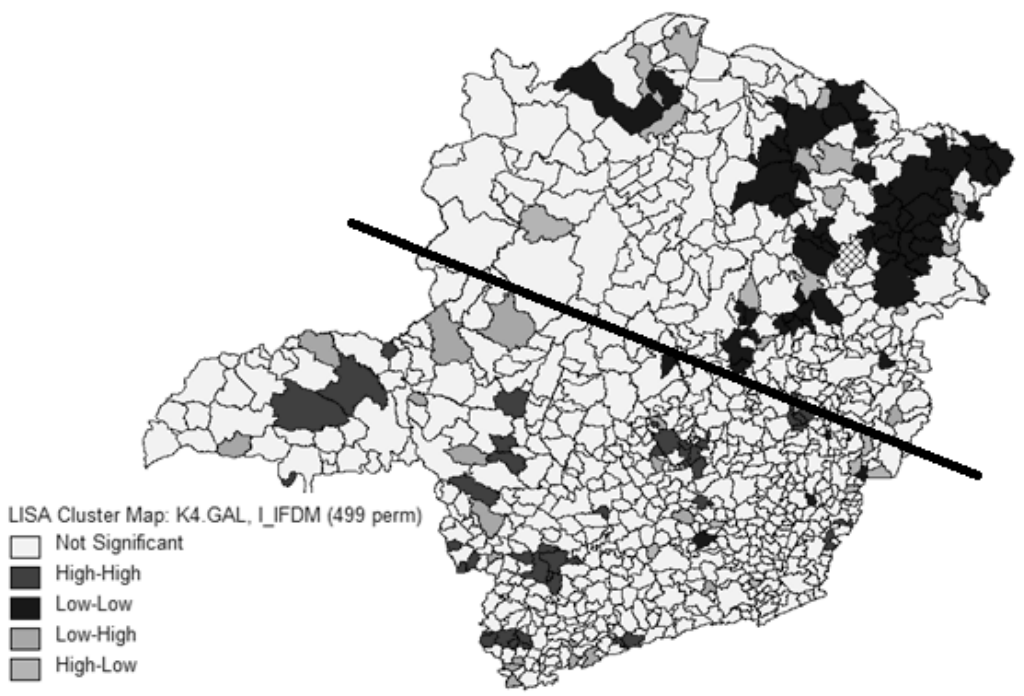

Fonte: Elaboração própria.

\section{Resultados}

Este capítulo contempla duas análises. A primeira revela a análise multivariada dos dados, via análise de correspondência, para identificar associações entre diferentes categorias das variáveis utilizadas; a segunda traz os resultados da regressão ponderada geograficamente, cujo foco é a compreensão da relação entre o indicador de desenvolvimento socioeconômico municipal e o arranjo institucional municipal, formado por um conjunto de variáveis institucionais ligadas à ação do Estado.

\subsection{Análise de Correspondência (AC)}

Os resultados da Tabela 4 referem-se à $\mathrm{AC}$ entre pares de variáveis, considerando-se sempre a variável IFDM em relação às preditoras. Nota-se que, dos arranjos institucionais (plan, gest, edu e sau), apenas os dois primeiros são significativos, revelando uma proximidade entre as categorias 3 (alto). Ou seja, municípios com alto IFDM estão associados à existência de mais instrumentos de planejamento (plan) e mais recursos para gestão (gest), os quais representam regiões que possuem, por exemplo, plano diretor, lei de zoneamento, mecanismos para a implantação de empreendimentos, programas de geração de trabalho e renda e algum tipo de consórcio ou convênio. No grupo de variáveis que representam os 
gastos do governo (gedu, gsau, inv, gout), são significativos os resultados dos gastos com educação, saúde e outros gastos. As tendências de associação são observadas entre as categorias semelhantes (com exceção para gedu e gout, que não apresentaram uma associação clara), ou seja, municípios com baixo gasto em saúde estão associados a baixos níveis do indicador IFDM, valendo também essa associação para as categorias 2 (médio indicador de gastos e médio IFDM) e 3 (alto indicador de gastos e alto IFDM).

Tabela 4 - Análise de correspondência simples para pares de variáveis

\begin{tabular}{lccccc}
\hline IFDM & $\begin{array}{c}\text { Prob > } \\
\text { chi }^{\mathbf{2}}\end{array}$ & $\begin{array}{c}\text { Inércia } \\
\text { total }\end{array}$ & $\begin{array}{c}\text { Dimensão I } \\
\text { Contribuição }^{*}\end{array}$ & $\begin{array}{c}\text { Dimensão 2 } \\
\text { Contribuição }^{\mathbf{1}}\end{array}$ & $\begin{array}{c}\text { Tendência } \\
\text { dos grupos }^{*}\end{array}$ \\
\hline Plan & $0,000^{*}$ & 0,592 & 2 & 3 & $3 / 3$ \\
Gest & $0,019^{* *}$ & 0,018 & 3 & 2 & $3 / 3$ \\
Edu & 0,705 & 0,002 & 2 & 1 & $1 / 1,2 / 2,3 / 3$ \\
Sal & 0,630 & 0,003 & 1 & 1 & $1 / 1,2 / 2.3 / 3$ \\
Gedu & $0,006^{*}$ & 0,017 & 3 & 1 & indefinido \\
Gsau & $0,000^{*}$ & 0,039 & 1 & 3 & $1 / 1,2 / 2.3 / 3$ \\
Inv & 0,131 & 0,008 & 2 & 3 & $1 / 1,2 / 2.3 / 3$ \\
Gout & $0,039^{* *}$ & 0,012 & 3 & 2 & indefinido \\
\hline
\end{tabular}

Fonte: Elaboração própria.

Nota: * $1 \%$ e *" $5 \%$ de significância; ${ }^{1}$ Dimensão 2 com percentual acumulado superior a 98\%.

Nos resultados da análise de correspondência múltipla (ACM), que é geralmente vista como uma extensão da análise de correspondência simples para mais de duas variáveis, tem-se uma tabela multiponto (Mapa de Correspondência). Da mesma forma como na $\mathrm{AC}$, a saída da $\mathrm{ACM}$ traz as inércias principais, contudo não traz o valor do qui-quadrado $\left(\mathrm{chi}^{2}\right.$ ), o qual é tomado como uma medida de dissimilaridade entre as linhas e as colunas. Nos resultados da ACM, ainda podem ser observados a massa, a inércia e as contribuições de cada variável. Optou-se, para melhor visualização, por se aplicar o método de ACM em duas etapas. Na primeira são plotadas as variáveis do grupo institucional (plan, gest, edu, sau) e o IFDM (ver Figura 3).

O Mapa de Correspondência indica uma associação entre as categorias 3 (alto) para o IFDM, "plan", "gest" e "edu" e também entre as categorias 0 e 1 (baixo) para o IFDM, "plan", "edu", "sau" e "gest". Além disso, considerando-se a maior contribuição da dimensão 1 (horizontal), observa-se a clara divisão entre as categorias do tipo baixo e alto. Ou seja, os municípios com alto IFDM estão associados aos altos valores dos indicadores institucionais para educação (por exemplo, existência de planos de educação e conselhos), planejamento (por exemplo, exis- 
tência de conselho de política urbana e plano diretor) e gestão (políticas de apoio ao primeiro emprego e políticas de geração de trabalho e renda, por exemplo).

Vale destacar que a distância entre o grupo da categoria alto e o grupo da categoria baixo revela uma forte associação negativa dessas variáveis para os municípios mineiros. Por fim, observa-se que o grupo da categoria 3 indica forte associação entre as variáveis, dada a distância dos pontos até a origem.

Figura 3 - Mapa de Correspondência: IFDM e variáveis institucionais

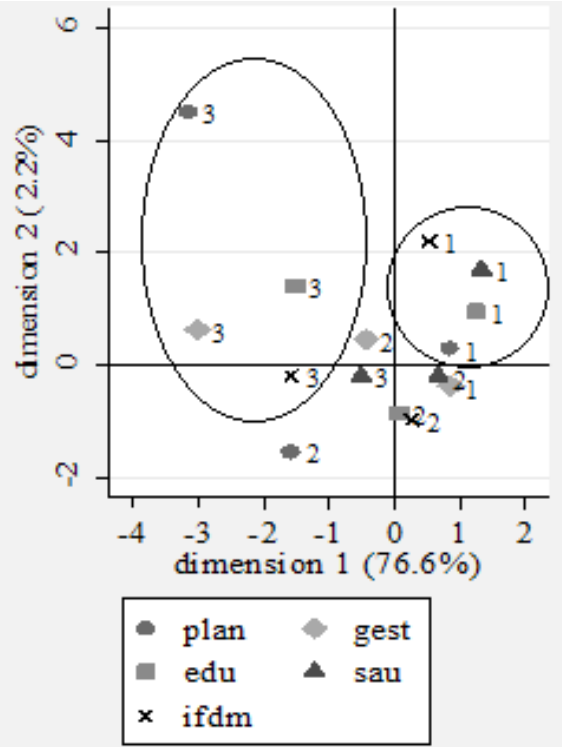

Fonte: Elaboração própria.

Nota: Coordenadas em normalização principal. Inércia total: 0,032. 
Na segunda etapa é analisado o grupo dos gastos públicos e o IFDM (Figura 4). Neste caso percebe-se uma forte associação entre a categoria 3 (alto) para gastos com educação, saúde e outros; entre a categoria 2, uma associação relativamente mais baixa para o mesmo grupo de gastos; e entre a categoria 1 também uma associação relativamente mais baixa entre os gastos com educação, saúde e outros.

Figura 4 - Mapa de Correspondência: IFDM e gastos do governo

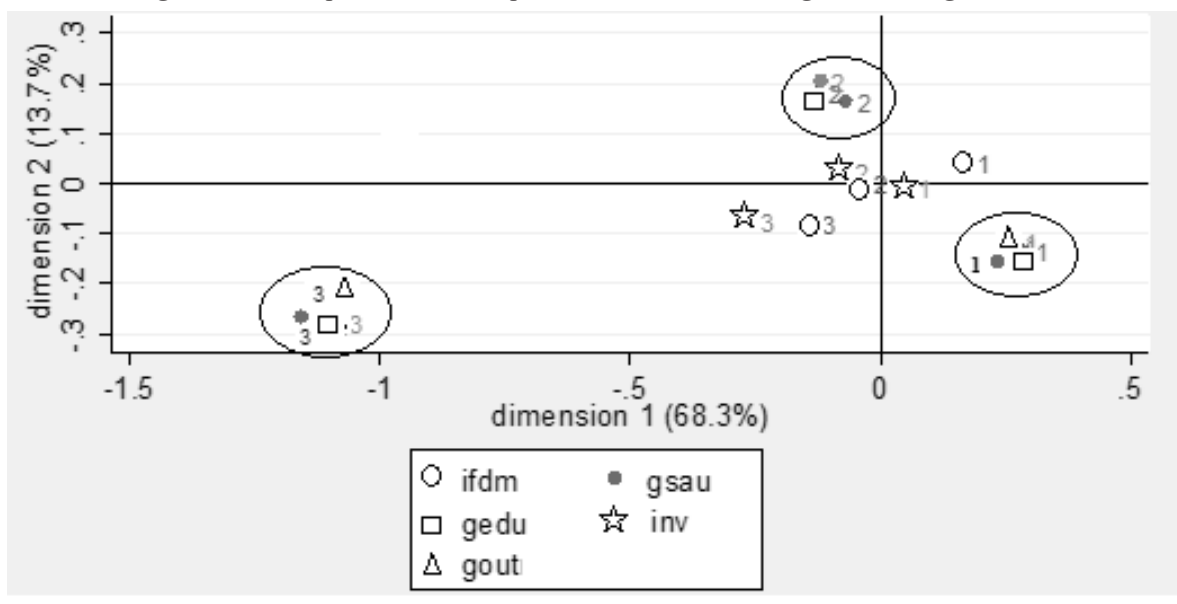

Fonte: Elaboração própria.

Nota: Coordenadas em normalização principal. Inércia total: 0,126.

Apesar das variáveis inv (esforço investimento do governo) e IFDM estarem perto da origem, observa-se uma fraca associação entre suas correspondentes categorias. De qualquer forma, dada a maior contribuição da dimensão 1 (horizontal) para explicar a associação dessas variáveis, o padrão alto/alto, médio/médio e baixo/baixo é evidente.

\subsection{Regressão Ponderada Geograficamente 9}

Optou-se pela estimação de três modelos para fins de comparação. O primeiro contempla o total das variáveis selecionadas para o arranjos institucional, incluindo os indicadores formulados a partir dos dados da MUNIC e os gastos do governo municipal em áreas selecionadas; os outros dois modelos possuem outras combinações de variáveis dos gastos do governo. Os resultados bem como alguns critérios de ajuste e seleção são apresentados na Tabela 5. A partir desses, parte-se para a análise do modelo 1, dado que os outros não apresentam inovações em

9 O software utilizado para a análise é o GWR4. 
termos dos sinais dos coeficientes ou do comportamento dos resíduos. Além disso, a redução do número de variáveis de gastos do governo (modelo 2) ou uma composição desses gastos (modelo 3) reduz a significância da variabilidade geográfica dos termos.

Os resultados do modelo 1 global revelam que, para a dimensão institucional, apenas a variável plan mostra-se significativa. Ou seja, o município ser do tipo que apresenta mais instrumentos para planejamento municipal (existência de conselho de política urbana, existência de legislações específicas sobre melhoria urbana, existência de plano diretor, entre outros) está associado positivamente a maiores valores do IFDM. Já do grupo das variáveis dos gastos públicos, todos os coeficientes são significativos no modelo global. Ou seja, gastos per capita com saúde, no esforço de investimento e nos outros gastos per capita estão diretamente associados ao IFDM. A exceção são os gastos per capita em educação, que apresentaram sinal negativo, revelando uma relação inversa entre gastos em educação e o indicador de desenvolvimento. 


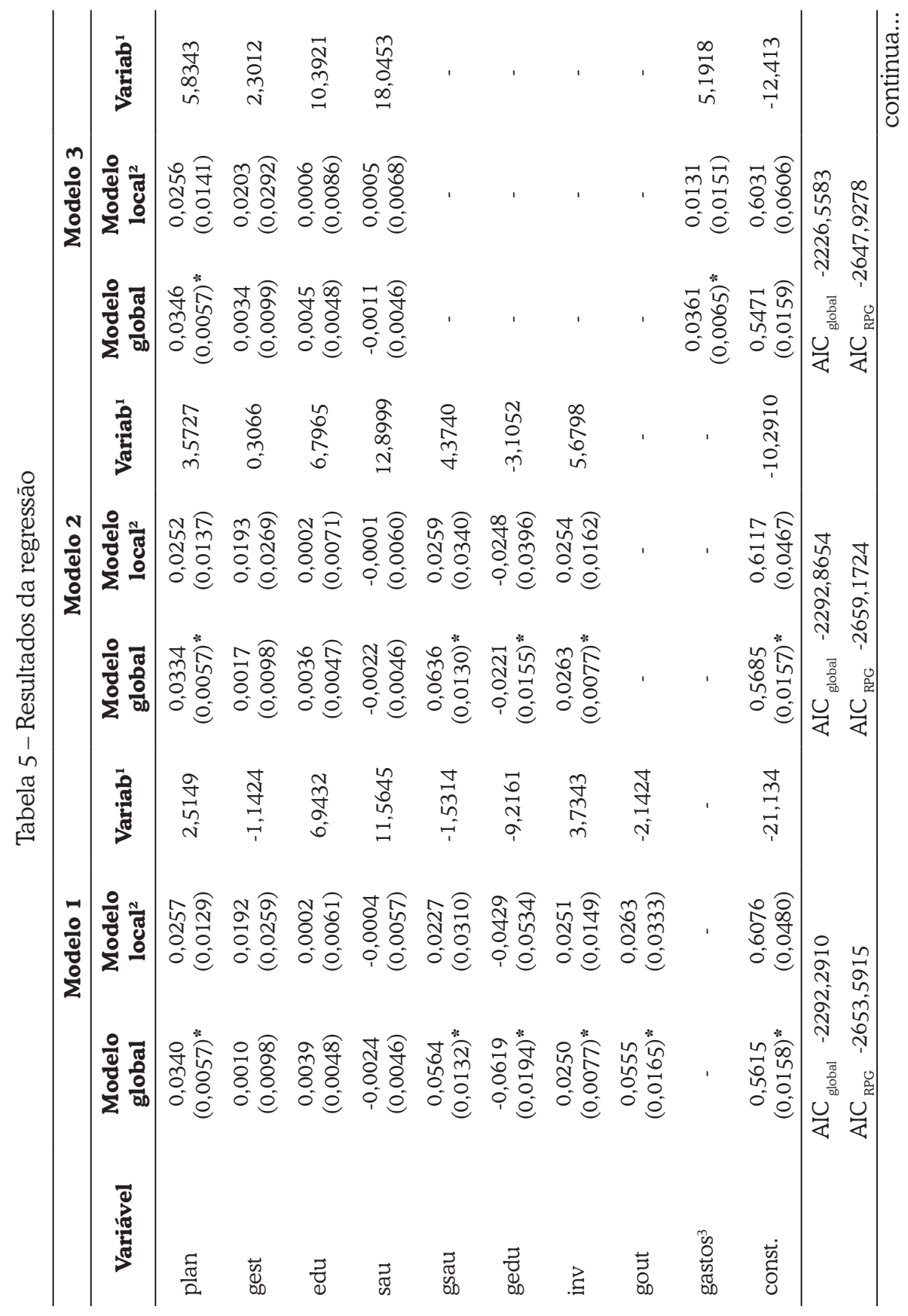




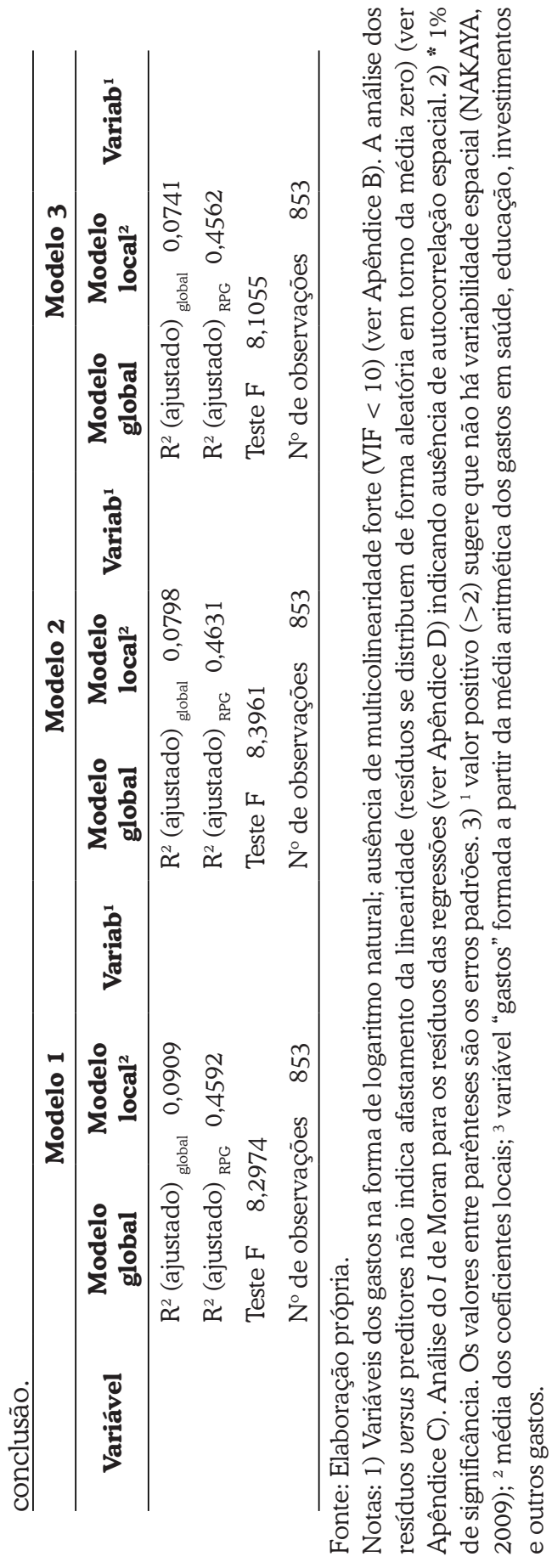


Entretanto, o modelo local ajusta-se melhor aos dados em relação ao modelo global, tendo em vista que o valor do critério de informação de Akaike é menor para o modelo local $\left(\mathrm{AIC}_{\mathrm{RPG}}\right.$ : $-2653,59<\mathrm{AIC}_{\text {global }}$-2292,29). Além disso, 46\% da variação do IFDM podem ser explicados pelos preditores do modelo local (ajuste muito superior aos $9 \%$ observados no modelo global). Dessa forma, uma regressão para cada unidade espacial parece ser mais adequada. Para confirmar a pressuposição de melhor ajuste do modelo local, o teste de análise de variânica (Anova) é realizado, sendo que o valor da estatística $F$ de 8,3 leva à rejeição da hipótese nula de que o modelo local não melhora os resultados do modelo global.

Para o modelo local, os testes de variabilidade geográfica indicam se os parâmetros estimados exibem não estacionariedade espacial. Assim, considerando-se os valores positivos e acima de 2 , observa-se que as variáveis institucionais plan, edu e sau não apresentam variabilidade espacial, ou seja, não se mostraram significativas para explicar o nível do IFDM dos municípios mineiros em nível local. Já a variável gest apresenta-se significativa. Os coeficientes locais estimados pelo modelo RPG são apresentados na Figura 5. Ademais, as variáveis de gastos públicos se mostram significativas, revelando que os gastos locais se associam positivamente ao IFDM (com exceção do gasto per capita em educação, que apresenta sinal negativo).

Figura 5 - Coeficientes locais da variável gest

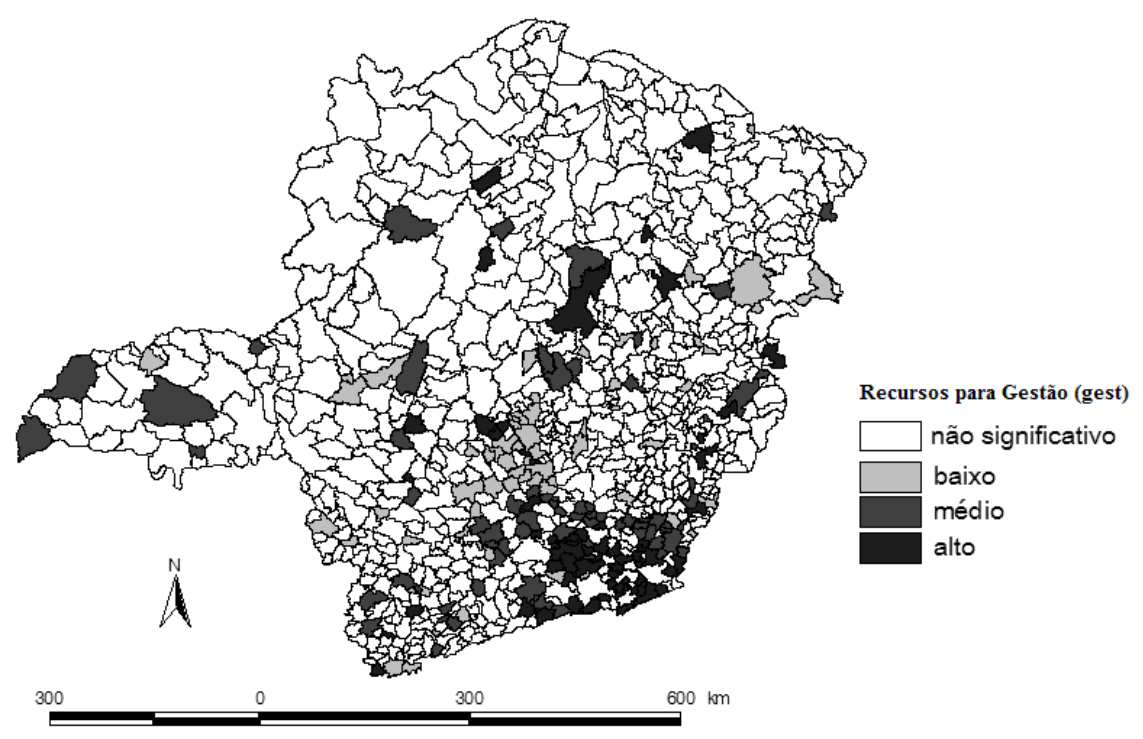

Fonte: Elaboração própria.

Nota: Coeficientes categorizados (baixo, médio e alto) com base no desvio padrão. 
Os resíduos do modelo RPG são analisados quanto à autocorrelação espacial por meio da estatística I de Moran e do c de Geary. São testadas diversas matrizes de ponderação espacial, contudo não há indicação da presença de dependência espacial no modelo de RPG. Assim, é possível analisar as relações (locais) existentes entre o indicador de desenvolvimento (IFDM) e as variáveis explicativas do grupo institucional e do grupo dos gastos públicos.

Para a variável gest, que representa um indicador institucional formado por fatores como a existência de mecanismos de incentivo a empreendimentos, políticas para geração de emprego e renda, apoio do setor privado e consórcios públicos, observa-se uma concentração de coeficientes da categoria alto na parte Sul/Sudeste do estado. Assim, em municípios como Barbacena e Santos Dumont, os quais estão no grupo com altos níveis da variável gest (recursos para gestão), verifica-se uma relação positiva com altos níveis do IFDM (ver Figura 5).

As regiões com altos valores de coeficientes para a variável gest (recursos para gestão) contemplam municípios mais desenvolvidos e que possuem relativamente mais instrumentos institucionais como programas de geração de trabalho e renda, políticas de apoio ao primeiro emprego e consórcios ou convênios específicos para desenvolvimento urbano ou emprego/renda.

Já a representação dos coeficientes locais para o grupo dos gastos do governo está apresentada nas Figuras 6. 
Figura 6 - Coeficientes locais para gasto per capita em educação (6a), gasto per capita em saúde (6b), esforço de investimento (6c) e outros gastos (6d)
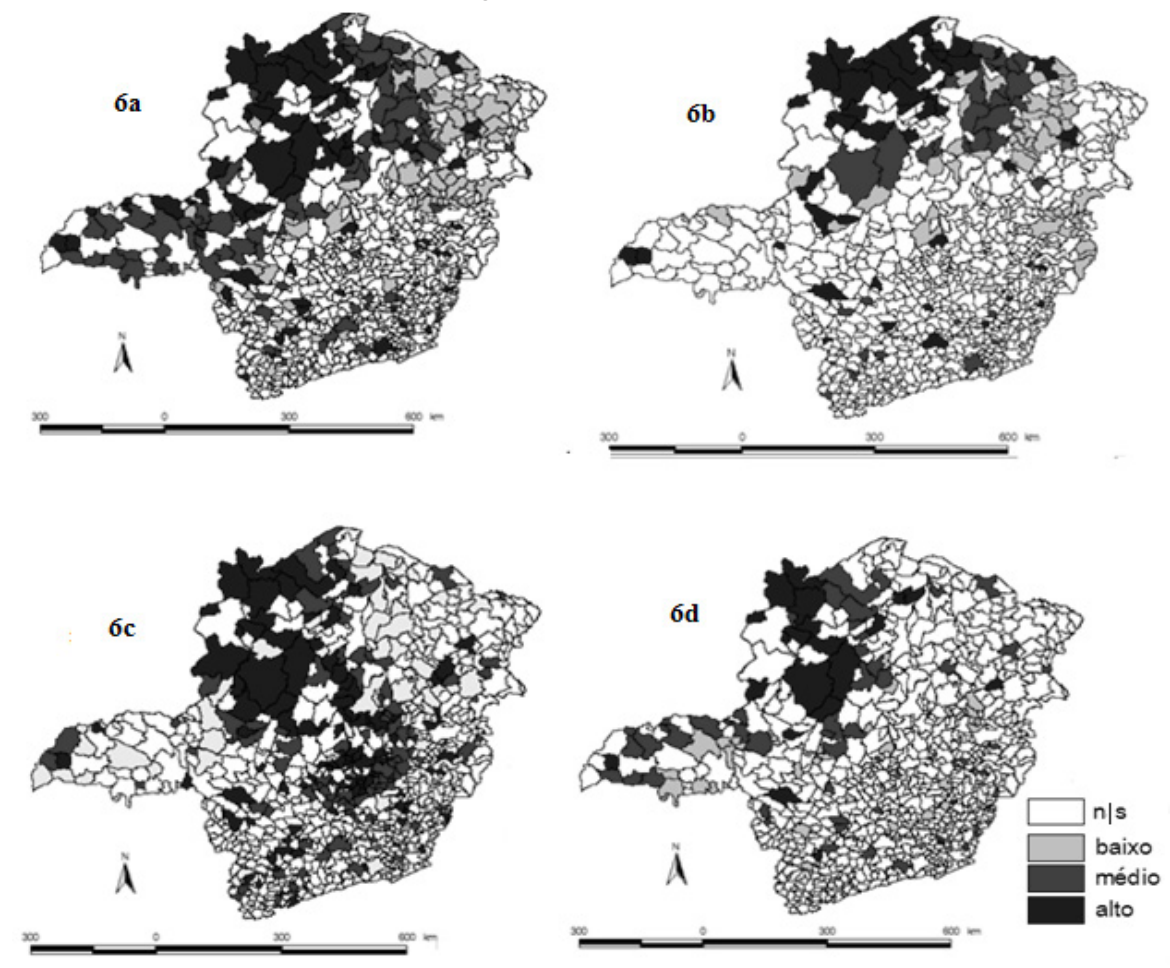

Fonte: Elaboração própria.

Nota: Coeficientes categorizados (baixo, médio e alto) com base no desvio padrão.

No caso do gasto per capita em educação (6a), ocorre uma concentração de coeficientes da categoria alto na parte Noroeste do estado, ou seja, em municípios como Arinos, Buritis e João Pinheiro, elevados níveis de gastos per capita com educação estão relativamente mais associados a menores níveis do IFDM (coeficiente negativo). Já para o gasto per capita com saúde (6b), ocorre uma concentração da categoria alto na parte Norte do estado, indicando que nos municípios como Jaíba e Januária, por exemplo, altos níveis de gasto per capita com saúde representam uma associação relativamente maior com elevado valor do IFDM. Para a variável inv (6c) (esforço de investimento), a concentração da categoria alto está na parte Noroeste e central do estado, revelando que nos municípios como Betim e Sete Lagoas, por exemplo, valores maiores do esforço em investimento estão relativamente mais associados a um maior nível do IFDM. Por sua vez, para a variável gout (6d) (outros gastos), a situação é semelhante, havendo uma associação direta entre o IFDM e esses outros gastos. 
Os resultados expostos na Figura 6, juntamente com a ACM (ver Figura 3), corroboram o padrão de forte associação entre municípios com alto IFDM e alto nível de gastos do governo em saúde, investimentos e outros gastos e baixo nível de gastos em educação, considerando a região mais ao Noroeste do estado. Dessa forma, sugere-se que políticas de gastos públicos em saúde, por exemplo, associam-se relativamente mais e de forma direta a altos valores do IFDM, e, de forma contrária, a focalização dos gastos públicos em educação nessas regiões associa-se relativamente mais e de forma inversa ao valor do IFDM dos municípios. Como este estudo aborda uma análise cross-section para o período de 2009, para os gastos com educação, sugere-se um caso de focalização de políticas públicas, no qual maiores gastos em educação são aplicados em regiões menos desenvolvidas.

Em resumo, considerando-se a área da saúde, os coeficientes locais gerados pela RPG indicam a relação direta entre os gastos do governo em atividades de saúde e o indicador IFDM. Para a área da educação, o sinal negativo indica uma relação inversa entre os gastos em educação e o IFDM, levantando a hipótese de focalização das políticas públicas. Sobre as variáveis das áreas de recursos para gestão (gest) e investimento (inv), os resultados apontam para uma associação positiva entre um ambiente institucional favorável (gest) e o desempenho do IFDM e também para uma associação positiva entre o esforço de investimento e o IFDM. Ou seja, municípios que apresentam um conjunto de elementos, como plano diretor, leis específicas de ocupação, leis de incentivo ao trabalho, entre outros, estão associados a um alto nível do IFDM e municípios que apresentam altos gastos relativos em investimento estão associados a um alto nível do IFDM.

\section{Considerações Finais}

O objetivo principal deste artigo foi analisar a relação entre o desenvolvimento socioeconômico e o arranjo institucional dos municípios de Minas Gerais, ou seja, como as leis, normas, diretrizes, apoio, fundos, entre outros influenciam o desempenho socioeconômico dos municípios mineiros. A discussão de desenvolvimento nesse corte territorial permite levantar hipóteses acerca das diferenças inter-regionais de associação entre um indicador de desenvolvimento e variáveis institucionais associadas à ação do Estado. Em uma região com grandes divergências socioeconômicas, como no caso de Minas Gerais, esse tipo de resultado pode corroborar e qualificar essas diferenças. Para tanto, uma análise de correspondência associada a uma análise econométrica espacial são ferramentas úteis ao revelarem as possibilidades de associação, tanto no nível global, quanto no nível local, entre outras dimensões para além daquelas puramente econômicas.

A análise incorpora variáveis quantitativas e qualitativas capazes de ampliar a visão acerca dos determinantes do desenvolvimento regional. Dessa forma, quan- 
do se elabora indicadores categóricos que refletem um arranjo institucional para diferentes áreas (educação, saúde, planejamento e gestão) e se busca uma associação desses indicadores com aqueles já disseminados (como o IFDM), espera-se, por hipótese, que estes últimos estejam associados a essas medidas institucionais.

Os resultados indicaram que existe uma associação entre o indicador socioeconômico e as variáveis institucionais. Essa relação foi identificada pela análise multivariada e complementada pela análise econométrica. Nesse modelo econométrico, o grupo de variáveis institucionais "recursos para gestão" (gest) mostrou-se estatisticamente significativo, corroborando a associação positiva entre essa variável e o IFDM, principalmente para municípios localizados na parte Noroeste do estado.

Complementar à discussão do desenvolvimento, os fatores endógenos reforçam a importância que o caráter local/regional assumiu nas últimas décadas, frente ao processo de globalização. Reforçando a síntese das políticas exógeno-endógenas, o Estado, enquanto instituição que articula uma rede de agentes locais, tem papel importante sobre a dinâmica de desenvolvimento. Não se deve menosprezar os efeitos que as instituições locais (cooperativas, sindicatos, associações, entre outras), bem como as regras e políticas que as constituem (legislação, cultura, capital social, dentre outras) exercem sobre as regiões.

Reforçando o papel do Estado na regulação e promoção do desenvolvimento, apesar das discussões que tangenciam a sua eficiência, este é um dos agentes responsáveis pela criação de arranjos institucionais que podem favorecer a articulação entre os demais agentes da economia. Deve-se pensar nas relações sociais inseridas em determinados contextos institucionais formais, como um processo ativo e contínuo de interação entre seus agentes, que, por sua vez, se expressa na forma de direitos e regras formais organizados pelo Estado e capazes de determinar o desenvolvimento, via redução de conflitos.

Assim, entender esse processo de desenvolvimento demanda uma análise das instituições que surgem da interação entre sociedade e Estado ao longo do tempo, compreendendo como os instrumentos institucionais formais elaborados a partir das políticas públicas podem ser construídos de modo a atenuar os desequilíbrios regionais em Minas Gerais.

\section{Referências}

ALBAGLI, S. Globalização e espacialidade: o novo papel do local. In: CASSIOLATO, J. E.; LASTRES, H. M. M. (Ed.). Globalização Ė inovação localizada. Brasília, DF: IBICT/MCT, 1999.

ALMEIDA, E. S. Econometria espacial aplicada. Campinas: Alínea, 2012.

ALVES, L. B.; BELDERRAIN, M. C.; SCARPEL, R. A. Tratamento multivariado de dados por análise de correspondência e análise de agrupamentos. In: ENCONTRO DE INICIAÇÃO 
CIENTÍFICA E PÓS-GRADUAÇÃO DO ITA. 13., 2007. Anais... São José dos Campos: Instituto Tecnológico de Aeronáutica, 2007. Disponível em < http://www.bibl.ita.br/xiiiencita/ MEC17.pdf > . Acesso em: 15 jan. 2013.

ANSELIN, L. Interactive techniques and exploratory spatial data analysis. In: LONGLEY, P. et al. (Ed.). Geographical information systems: principles, techniques, management and applications. New York: Wiley, 1999.

ARAÚJO, E. T.; MELO, V. P.; SCHOMMER, P. C. O desafio da sustentabilidade financeira e suas implicações o papel social das organizações da sociedade civil. In: CONFERÊNCIA LATINO AMERICANA Y DEL CARIBE, 5., 2005. Anais... Lima, Peru: ISTR, 2005.

BAUMONT, C. Spatial effects in housing price models: do house prices capitalize urban development policies in the agglomeration of Dijon (1999)? Dijon cedex, France: Université de Bourgogne, avril, 2004. (Discussion paper, non numerado).

CHANG, H. Chutando a escada: a estratégia do desenvolvimento em perspectiva histórica. São Paulo: Unesp, 2003.

. The political economy of industrial policy. Nova York: Palgrave Macmillian, 1996. COPPOLA, G.; GAROFALO, M. R.; MAZZOTTA, F. Industrial localisation and economic development: a case study. Fisciano: Centro di Economia del Lavoro e di Politica Economica Dipartimento di Scienze Economiche e Statistiche Università degli studi di Salerno, 2003. (Dicussion paper, n. 71).

CZERMAINSKI, A. B. Análise de correspondência. Piracicaba, 2004. Disponível em: < http:// ce.esalq.usp.br/tadeu/anabeatriz.pdf> . Acesso em: 15 jan. 2013.

DINIZ, C. C. Globalização, escalas territoriais e política tecnológica regionalizada no Brasil. Belo Horizonte: UFMG; Cedeplar, 2001. (Texto para discussão, n. 168).

DINIZ, C. C.; CROCCO, M. Bases teóricas e instrumentais da economia regional e urbana e sua aplicabilidade ao Brasil: uma breve reflexão. In DINIZ, C. C.; CROCCO, M. (Org.). Economia regional e urbana: contribuições teóricas recentes. Bahia: UFMG, 2006.

EVANS, P. Government action, social capital and development: reviewing the evidence on synergy. World Development, v. 24, n. 6, p. 1119-1132, 1996. Disponível em: < http://www. sciencedirect.com/science/article/pii/0305750X96000216 >. Acesso em: 05 fev. 2014.

EVERITT, B. S.; LANDAU, S.; LEESE, M. Cluster analysis. 4. ed. London: Arnold, 2001. FEDERAÇÃO DAS INDÚSTRIAS DO ESTADO DO RIO DE JANEIRO. IFDM. Disponível em: $<$ http://www.firjan.com.br/ifdm>. Acesso em: 15 jan. 2013.

FIANI, R. Cooperação e conflito: instituições e desenvolvimento econômico. Rio de Janeiro: Elsevier, 2011.

FOTHERINGAN, A. S.; BRUNDSDON, C.; CHARLTON, M. Geographically weighted regressions: the analysis of spatially varying relationships. New Jersey: Jonh Wiley $\mathcal{E}$ Sons, 2002.

FREITAS, M. V.; ALMEIDA, E. S. Existe realmente convergência de renda entre países? Estudos Econômicos, v. 45, n. 2, p. 287-316, 2015. 
FUNDAÇÃO JOÃO PINHEIRO. Índice Mineiro de responsabilidade social - IMRS. Disponível em: <http://www.fjp.gov.br/index.php/indicadores-sociais/-imrs-indice-mineiro-deresponsabilidade-social>. Acesso em: 15 jan. 2013.

GONÇALVES, M. T.; SANTOS, S. R. Aplicação da análise de correspondência a avaliação institucional da FECILCAM. In: ENCONTRO DE PRODUÇÃO CIENTÍFICA E TECNOLÓGICA, 4., 2009. Anais... Campo Mourão: Núcleo de Pesquisa Multidisciplinar, 2009. Disponível em: <http://www.fecilcam.br/nupem/anais_iv_epct/PDF/ciencias_ exatas/07_GON\%C3\%87ALVES_SANTOS.pdf.>. Acesso em: 15 jan. 2013.

GOWER, J. C.; HAND, D. J. Biplots. London: Chapman E Hall, 1996.

GREENACRE, M. J. Correspondence analysis in practice. 2. ed. Boca Raton, FL: Chapman $\mathcal{E}$ Hall; CRC, 2007.

GREENACRE, M. J. Theory and applications of correspondence analysis. London: Academic Press, 1984.

HEALEY, P. Collaborative planning: shaping places in fragmented societies. London: MacMillan, 1997.

IBGE. Informações básicas sobre municípios - MUNIC. Disponível em: <http://www.ibge.gov. br/home/estatistica/economia/perfilmunic > . Acesso em: 10 nov. 2013.

LEBART, L.; MORINEAU, A.; FÉNELON, J. P. Traitement des donnees statistiques: methodes et programmes. 2. ed. Paris: Dunod, 1977.

LEBART, L.; MORINEAU, A.; WARWICK, K. M. Multivariate descriptive statistical analysis: correspondence analysis and related techniques for large matrices. New York: John Wiley E Sons, 1984.

NAKAYA, T. GWR4 User Manual. GWR4 Windows application for geographically weighted regression modelling. University of St Andrews, 2009. Disponível em: <https://raw.githubusercontent.com/ gwrtools/gwr4/master/GWR4manual_409.pdf>. Acesso em: 05 de fev. 2015.

NORTH, D. Institutions, institutional change and economic performance. Cambridge, MA: Cambridge University Press, 1990.

REIS, M. C. Desenvolvimento local e espaços sociais ampliados. 2006. $161 \mathrm{f}$. Tese (Doutorado em Desenvolvimento Local e Espaços Sociais Ampliados) - Universidade Federal Rural do Rio de Janeiro, Rio de Janeiro, 2006.

RIBEIRO, E. C. A.; ALMEIDA, E. S. Convergência local de renda no Brasil. Economia Aplicada, v. 16, n. 3, p. 399-420, 2012.

SOUZA, A. C.; BASTOS, R. R.; VIEIRA, M. T. Análise de correspondência simples e múltipla para dados amostrais complexos. In: SIMPÓSIO NACIONAL DE PROBABILIDADE E ESTATÍSTICA, 19., 2010. Anais... São Paulo: SINAPE, 2010.

STATACORP. Stata: Release 11. Statistical Software. College Station, TX: StataCorp LP, 2009.

WILLIAMSON, O. The economic institutions of capitalism. Nova York: The Free Press, 1985. 


\section{Apêndịce A - Descrição das Variáveis da Munic que compõem as Variáveis Institucionais}

\begin{tabular}{|c|c|c|c|}
\hline $\begin{array}{l}\text { Legislação e instrumentos de pla- } \\
\text { nejamento no município (plan) }\end{array}$ & Código & Educação (edu) & Código \\
\hline $\begin{array}{l}\text { Conselho municipal de política urbana, } \\
\text { desenvolvimento urbano da cidade ou } \\
\text { similar }\end{array}$ & $\mathrm{A} 26$ & $\begin{array}{l}\text { Sistema municipal de ensi- } \\
\text { no próprio }\end{array}$ & A171 \\
\hline $\begin{array}{l}\text { O município possui legislação especí- } \\
\text { fica sobre zona e/ou área de interesse } \\
\text { social }\end{array}$ & A38 & $\begin{array}{l}\text { Lei de Diretrizes Orçamen- } \\
\text { tárias (LDO) }\end{array}$ & A175 \\
\hline Lei de parcelamento do solo & A47 & $\begin{array}{l}\text { Concessão de incentivos } \\
\text { fiscais para entidades edu- } \\
\text { cacionais }\end{array}$ & A180 \\
\hline Lei de zoneamento ou equivalente & A48 & $\begin{array}{l}\text { Conselho de controle e } \\
\text { acompanhamento social } \\
\text { do Fundef }\end{array}$ & A181 \\
\hline Código de obras & A49 & Conselhos escolares & A182 \\
\hline Lei específica de solo criado & A51 & $\begin{array}{l}\text { Conselho de alimentação } \\
\text { escolar }\end{array}$ & A183 \\
\hline $\begin{array}{l}\text { Lei específica de contribuição de me- } \\
\text { lhoria }\end{array}$ & A52 & $\begin{array}{l}\text { Conselho do transporte } \\
\text { escolar }\end{array}$ & A184 \\
\hline $\begin{array}{l}\text { Lei específica de operação urbana } \\
\text { consorciada }\end{array}$ & A53 & $\begin{array}{l}\text { Sistema municipal de en- } \\
\text { sino }\end{array}$ & A185 \\
\hline $\begin{array}{l}\text { Lei específica de estudo de impacto de } \\
\text { vizinhança }\end{array}$ & A54 & $\begin{array}{l}\text { Plano municipal de edu- } \\
\text { cação }\end{array}$ & A187 \\
\hline Código de posturas & A55 & $\begin{array}{l}\text { Conselho municipal de } \\
\text { educação }\end{array}$ & A211 \\
\hline Plano diretor & A56 & $\begin{array}{l}\text { Consórcio público intermu- } \\
\text { nicipal }\end{array}$ & A220 \\
\hline Recursos para a gestão (gest) & & $\begin{array}{l}\text { Consórcio público com o } \\
\text { Estado }\end{array}$ & A221 \\
\hline $\begin{array}{l}\text { Mecanismos de incentivo à implanta- } \\
\text { ção de empreendimento }\end{array}$ & A85 & $\begin{array}{l}\text { Consórcio público com o } \\
\text { governo federal }\end{array}$ & A222 \\
\hline $\begin{array}{l}\text { Programas ou ações de geração de } \\
\text { trabalho e renda }\end{array}$ & A110 & $\begin{array}{l}\text { Convênio de parceria com } \\
\text { o setor privado }\end{array}$ & A223 \\
\hline $\begin{array}{l}\text { Política de apoio ao primeiro emprego } \\
\text { de jovens e adolescentes no município }\end{array}$ & A119 & $\begin{array}{l}\text { Apoio do setor privado ou } \\
\text { de comunidades }\end{array}$ & A224 \\
\hline Consórcio público intermunicipal & A 120 & Saúde (sau) & \\
\hline Consórcio público com o Estado & A121 & $\begin{array}{l}\text { Conselho municipal de } \\
\text { saúde }\end{array}$ & A391 \\
\hline
\end{tabular}


conclusão.

\begin{tabular}{l|c|l|c}
\hline $\begin{array}{l}\text { Legislação e instrumentos de pla- } \\
\text { nejamento no município (plan) }\end{array}$ & Código & Educação (edu) & Código \\
\hline $\begin{array}{l}\text { Consórcio público com o governo } \\
\text { federal }\end{array}$ & A122 & Fundo municipal de saúde & A399 \\
\hline $\begin{array}{l}\text { Convênio de parceria com o setor } \\
\text { privado }\end{array}$ & A123 & Plano municipal de saúde & A401 \\
\hline $\begin{array}{l}\text { Apoio do setor privado ou de comu- } \\
\text { nidades }\end{array}$ & A124 & $\begin{array}{l}\text { Programa de saúde da } \\
\text { família }\end{array}$ & A409 \\
\hline $\begin{array}{l}\text { Consórcio público com o Estado } \\
\text { Consórcio público com o governo } \\
\text { federal }\end{array}$ & A126 & $\begin{array}{l}\text { Consórcio público intermu- } \\
\text { nicipal }\end{array}$ & $\begin{array}{l}\text { Consórcio público com o } \\
\text { Estado }\end{array}$ \\
\hline $\begin{array}{l}\text { Convênio de parceria com o setor } \\
\text { privado }\end{array}$ & A128 & $\begin{array}{l}\text { Consórcio público com o } \\
\text { governo federal }\end{array}$ & A415 \\
\hline $\begin{array}{l}\text { Apoio do setor privado ou de comu- } \\
\text { nidades }\end{array}$ & A129 & $\begin{array}{l}\text { Convênio com o setor } \\
\text { privado }\end{array}$ & A417 \\
\hline & $\begin{array}{l}\text { Apoio do setor privado ou } \\
\text { de comunidades }\end{array}$ & A418 \\
\hline
\end{tabular}

Fonte: Elaboração própria.

Apêndice B - Análise de Linearidade: Resíduos versus Preditores

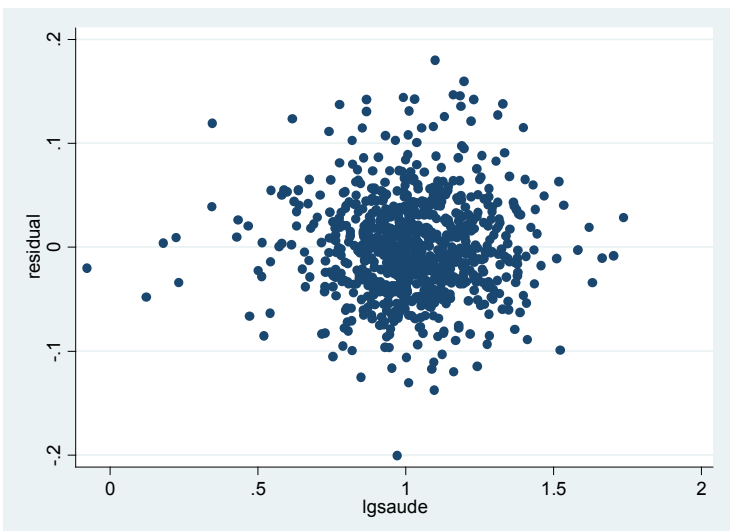



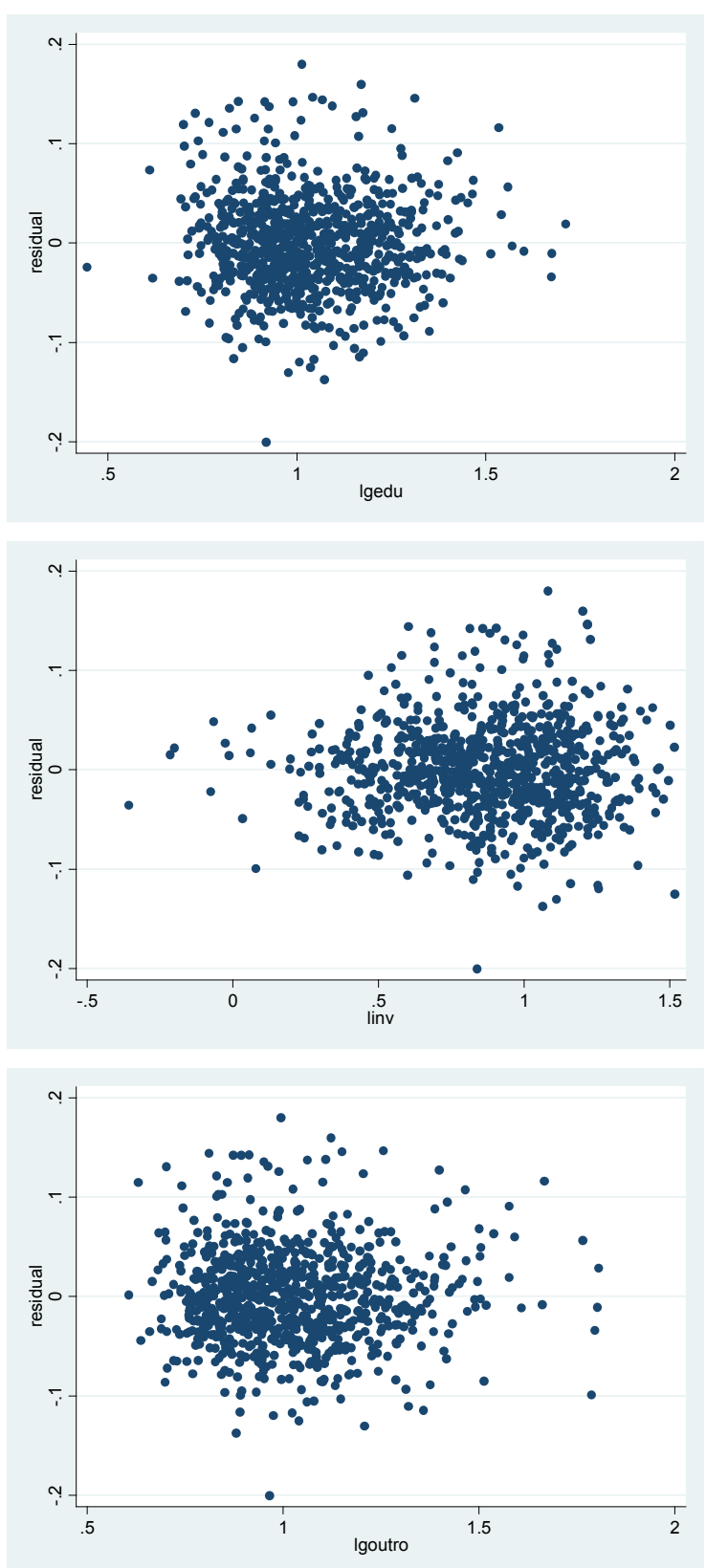

Fonte: Elaboração própria.

Nota: Os resíduos se distribuem aleatoriamente ao redor da média (zero). 
Apêndice C - Análise de Multicolinearidade

\begin{tabular}{lr}
\hline Variável & VIF \\
\hline plan & 1,08 \\
gest & 1,09 \\
edu & 1,05 \\
sau & 1,02 \\
gsau & 1,48 \\
gedu & 2,3 \\
inv & 1,01 \\
gout & 2,1 \\
\hline Média VIF (variance inflation factor) & 1,39 \\
\hline
\end{tabular}

Fonte: Elaboração própria.

Apêndice D - I de Moran para Resíduos e Resíduos Padronizados (Modelos 1,2 e 31
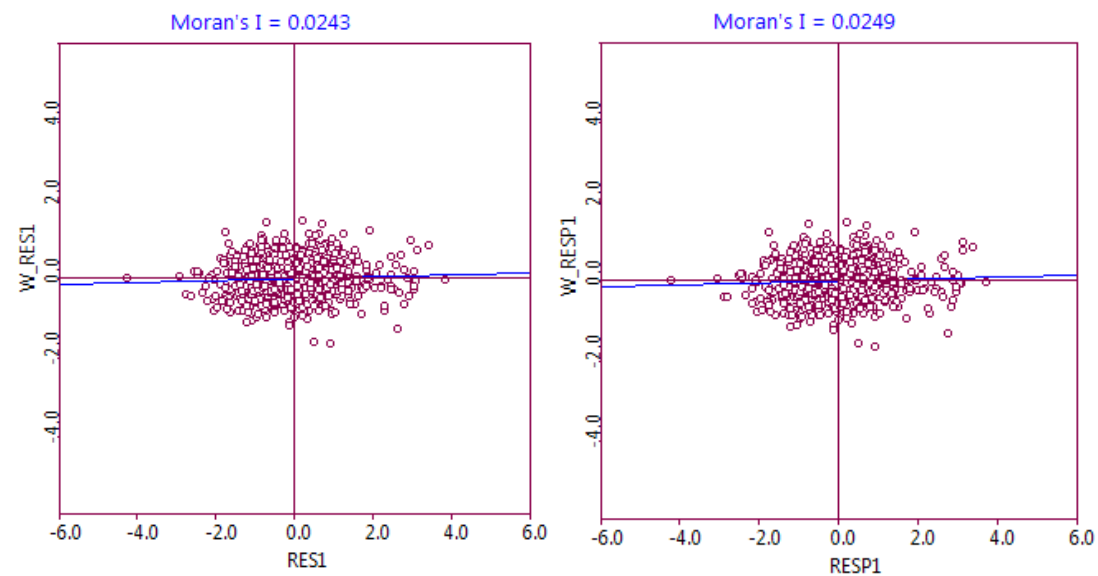

Modelo1 

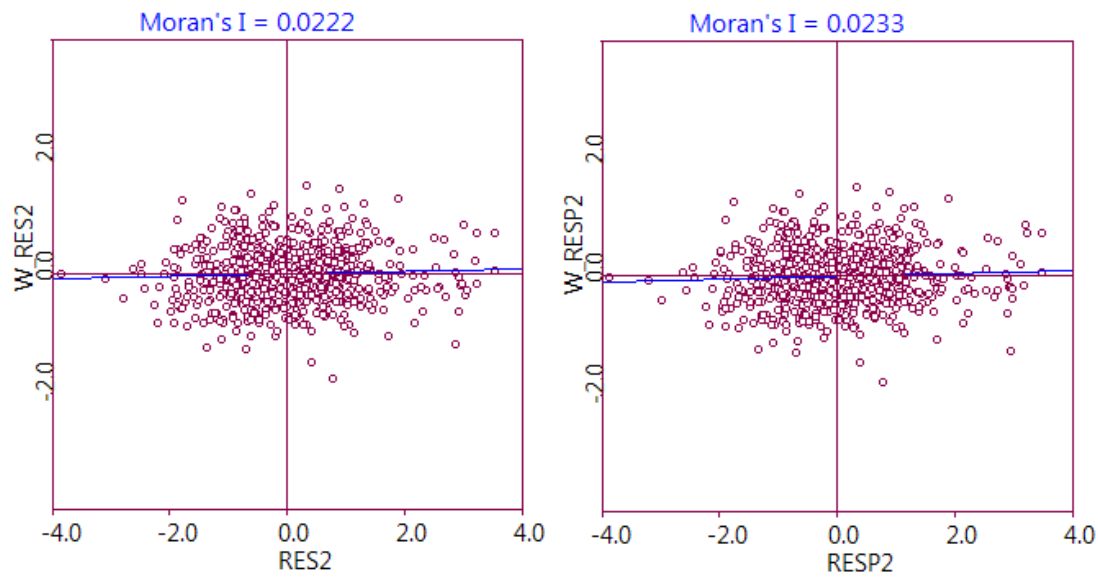

Modelo 2
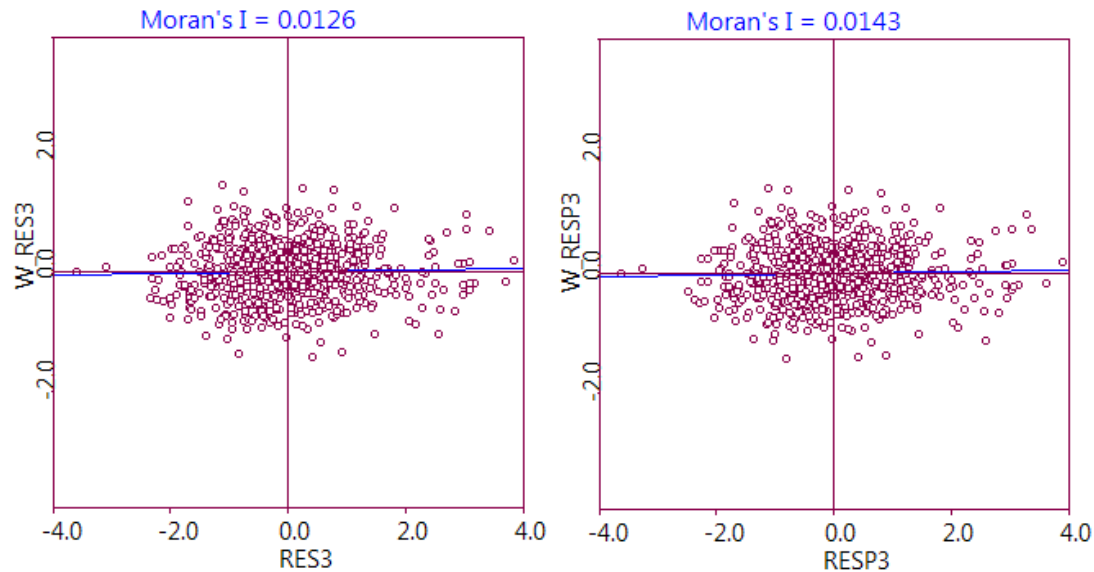

Modelo 3

Fonte: Elaboração própria.

Nota: Os resíduos se distribuem aleatoriamente ao redor da média (zero).

Recebido em: 05/06/2014.

Aceito em: 26/10/2016. 